\title{
Molecular Mechanisms of Platinum Resistance in Ovarian Cancer
}

\author{
Gonzalo Tapia and Ivan Diaz-Padilla \\ Additional information is available at the end of the chapter \\ http://dx.doi.org/10.5772/55562
}

\section{Introduction}

In 2012, approximately 22,280 women will be diagnosed with ovarian carcinoma in the United States and roughly 15,500 will die from this disease, ranked the most common cause of death among gynecologic malignancies in developed countries [1]. Most women with epithelial ovarian cancer (EOC) present with advanced disease (stage III or IV) at the time of diagnosis. This phenomenon is mainly due to the lack of specific symptoms until disease has spread beyond the ovaries, at which time the chance of cure is dramatically reduced [2]. Current standard treatment of ovarian cancer, in both early and advanced stages, consists of complete cytoreductive surgery followed by chemotherapy, usually based on a platinum and a taxane doublet $[3,4,5]$. Initial response rate (RR) is high $(70 \%-80 \%)$; but the majority of patients with advanced disease relapse within two years. Recurrent ovarian cancer is not curable, due to the development of chemoresistance [6,7]. The Gynecologic Oncology Group (GOG) adopted the definition of sensitivity to chemotherapy (or sensitivity to platinum) in EOC based on clinical criteria from retrospective case series [8]. When patients were re-challenged with a platinum compound the longer the interval from the last dose of platinum patients had received the better the response (and outcome) was. This clinical observation set the base for the current classification of platinum resistance in relapsed EOC (Figure 1), and allowed the commonly used stratification criteria in clinical trials of recurrent EOC. Platinum-resistant disease is also characterized by resistance to other cytotoxic agents, and not necessarily only resistant to platinum. However, current treatment for platinum-resistant EOC consists of chemotherapy agents whose mechanism of action is somewhat different from that of platinum compounds [9].

Since platinum compounds are the backbone in the systemic treatment of EOC, there is great interest in elucidate the molecular mechanisms contributing to platinum resistance in this disease. The present chapter will provide a comprehensive basic and translational update with 


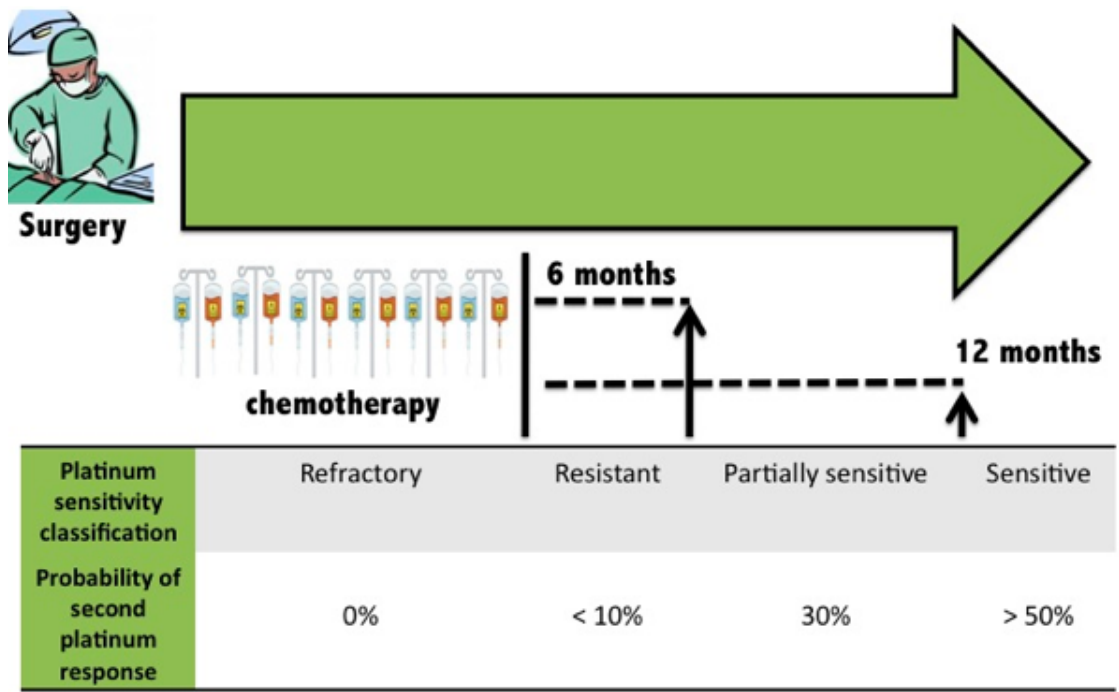

Figure 1. Platinum-resistance definition by the Gynecologic Oncology Group (GOG). Platinum sensitivity is classified as resistant, partially sensitive, or sensitive, according to the time relapsed since finishing first-line treatment. Probability of re-treatment response is shown for each group of patients.

regards to biological pathways implicated in the development of platinum resistance, focusing on ovarian cancer therapeutics.

\section{Cisplatin: Mechanism of action}

Once introduced actively into the cell mediated by a copper transporter (CTR1), the molecule is activated through a series of aquation reactions, in which one of the chloride ligands is slowly displaced by water. Aquated cisplatin avidly binds DNA, with a predilection for nucleophilic N7-sites on purine bases [10]. The first step of the reaction involves the formation of monoadducts. These monoadducts may then react further to form intra-strand and inter-strand crosslinks. The cytotoxic activity of platinum compounds has been related to binding with DNA and the production of intra-strand and inter-strand crosslinks, as well as the formation of adducts that cause conformational DNA changes, impeding the separation of both DNA strands, which subsequently impairs replication and inhibits DNA synthesis [11]. Intra-strand cross-links are the most abundant products of the interaction with DNA (around 70\% of all platinum-DNA linking products). These lesions cause significant distortions in the DNA that can be recognized by one or more DNA binding proteins. These proteins can either initiate DNA damage repair or signal for apoptosis. Platinum-mediated programmed cell death is caused by cell cycle arrest in the G2-phase, although the pathways from platinum-DNA binding to apoptosis are not completely understood [12]. 
Other proposed mechanisms of cisplatin cytotoxicity include mitochondrial damage, decreased ATPase activity, and altered cellular transport mechanisms. Mitochondria seem to play a role in the cell death. This is believed to be mediated by their interaction with nuclear DNA [13]. Additionally, mitochondria are thought to be a major target of cisplatin and mitochondrial DNA is heavily damaged by cisplatin leading to mitochondrial loss of energy production and decreasing the ATPase activity $[14,15]$. Another proposed mechanism of action is the transporter-mediated uptake. Entering the cells is the first step for cisplatin to exert its toxic effects. In recent years there has been increasing evidence that the cellular uptake of cisplatin is mediated, at least in part, by transport proteins. Several transporters, which are expressed on the cell membranes, have been associated with cisplatin transport across the plasma membrane and across the cell: the copper transporter 1 (Ctr1), the copper transporter 2 (Ctr2), the P-type copper-transporting ATPases ATP7A and ATP7B [16,17].

\section{Platinum analogues and ovarian cancer therapeutics}

Despite the clear advantage in OS and PFS obtained with cisplatin-paclitaxel, it was immediately noted that this regimen carries a significant toxicity, namely peripheral neurotoxicity and nephrotoxicity [18]. Another important limitation of cisplatin-paclitaxel chemotherapy is the difficulty in administering it as an outpatient regimen. Prior to the introduction of paclitaxel, several studies had established that cisplatin and carboplatin are therapeutically equivalent in women with advanced epithelial ovarian cancer. Furthermore, carboplatin is associated with significantly lower neurotoxicity and renal toxicity and that the combination of carboplatin and 3-h infusion paclitaxel can be given as an outpatient schedule. This was also demonstrated in a Cochrane meta-analysis [19].

Three trials have investigated the equivalence of carboplatin and cisplatin in combination with paclitaxel in the first-line setting [20,21,22]. Given the evidence of a more favorable toxicity profile and ease of delivery, the carboplatin-paclitaxel combination has become an almost universal choice in the management of ovarian cancer, and is the standard comparator in all the recent trials performed in this disease.

\section{Mechanisms of cellular resistance to platinum agents}

Even though initial responsiveness to platinum-based therapy is high in ovarian cancer, the majority of patients relapse. Several mechanisms of cellular resistance to platinum compounds have been described. These mechanisms can be classified in two groups: 1) those that the limit the formation of cytotoxic platinum-DNA adducts, and 2) those that prevent cell death occurring after platinum-DNA adduct formation [11,23]. A better understanding of the molecular basis of cisplatin resistance may lead to new antitumor strategies that will sensitize unresponsive ovarian cancers to cisplatin-based chemotherapy. 


\subsection{Reduced intracellular drug accumulation}

Decreased cellular uptake of cisplatin by resistant cells is one of the major mechanisms of resistance described in vitro. The mechanism responsible for reduced cisplatin accumulation in resistant cells may be ascribed to either an inhibition in drug uptake, an increase in drug efflux, or both. Cisplatin and its analogues may accumulate within cells by passive diffusion or facilitated transport. The copper transporter-1 (CTR1) regulates the influx of cisplatin and its analogues into the cell. This is supported by the evidence in cell lines of deletion of the yeast CTR1 gene, which encodes a high-affinity copper transporter, results in increased cisplatin resistance and reduced intracellular accumulation of cisplatin in various cell lines including ovarian cancer $[24,25]$. In human ovarian cancer cell lines it has been demonstrated that copper and cisplatin are competitive inhibitors for the transport of each other into the cell and cause a rapid down-regulation of CTR1 expression mediated by internalization of this transporter from the plasma membrane and subsequent [26]. Two copper exporters, ATP7A and ATP7B, have also been proposed to be involved in cellular resistance to cisplatin [27]. ATP7A is thought to sequester platinum agents in intracellular compartments, preventing their reaction with nuclear DNA. ATP7A is over-expressed in some cisplatin-resistant ovarian carcinoma cell lines. Additionally, ovarian cancer patients with ATP7A expression have a lower survival rate than patients with undetectable levels of expression, as determined by ATP7A immunostaining [28]. Over-expression of ATP7B in primary ovarian carcinomas and ovarian carcinoma cell lines resulted in resistance to cisplatin, with only $60 \%$ of the cisplatin accumulation present in ATP7B-expressing cells compared to vector control [29].

MRP-related transport proteins are involved in the active efflux of platinum drugs. MRP is a member of the ABC (adenosine triphosphate-binding cassette) family of transport proteins that participates in the efflux of anticancer drugs from cells. Thus, it has been speculated that deregulation of some of the MRP components may influence platinum resistance [30]. The MRP gene family is composed of at least seven members (MRP1-7) but recent reports reinforced the notion that MRP2 expression levels can be important in predicting the sensitivity of tumors to platinum-based therapies [31,32]. MDR1 encodes an integral membrane protein named P-glycoprotein (Pgp) or an ATP-binding cassette subfamily B, member 1, which acts as a drug efflux pump [33]. This protein is a transmembrane transporter that resides in the plasma membrane of many cells, including cancer cells that are multidrug resistant. Pgp recognizes a wide range of anticancer drugs and was shown to reduce intracellular concentrations of a variety of cytotoxic drugs, including platinum agents. Pgp activity results in blunted chemotherapy-induced cytotoxicity in vitro and in vivo. Moreover, anticancer drugs were found to induce MDR1 gene. Since Pgp alone can mediate resistance to a whole array of drugs through drug efflux, it is an attractive target for the improvement of anticancer therapy. In theory, co-administration of transporter inhibitors with Pgp-substrate anticancer drugs could reverse MDR and improve treatment outcome. Clinical trials aimed at specifically inhibiting the function of Pgp have given mixed results, but in at least some cases this inhibition has resulted in improved tumor shrinkage and increased patient survival. Unfortunately, Pgp inhibitors such as PSC-833 (Valspodar) induced pharmacokinetic interactions that limited drug clearance and metabolism of the 
concomitantly administered chemotherapy, thereby elevating plasma concentrations beyond acceptable toxicity [34]. It is thus clear that the Pgp overexpression can be a cause of failure of anticancer chemotherapy and be associated with worse prognosis in patients with ovarian and breast cancers, sarcomas and other malignancies [29,35,36].

\subsection{Intracellular cisplatin inactivation}

Glutathione (gamma-glutamylcysteinylglycine: GSH), the most abundant intracellular thiol, contributes (along with methionine, metallothionein and other cysteine-rich proteins) to detoxify many cellular toxins, including cisplatin and its analogues. Part of the cytoplasmic cisplatin reacts with DNA, which ultimately lead to the activation of the apoptosis cascade in response to DNA damage. However, a major fraction of intracellular cisplatin can be converted into cisplatin-thiol conjugates by GSH-S-transferase $\pi$, and these conjugates are ultimately inactivated. Both GST $\pi$ and $\gamma$-glutamylcysteine synthetase ( $\gamma$-GCS), the latter being the enzyme involved in GSH synthesis, have been associated with cisplatin resistance in ovarian, cervical and lung cancer cell lines [37,38,39].

Thus, reducing intracellular glutathione levels would seem a rational strategy to overcome platinum resistance. To that end, a novel glutathione analog prodrug, canfosfamide, initiated clinical development in ovarian cancer. Canfosfamide (TLK286) works by targeting tumors that over-express glutathione S-transferase (GST) P1-1, increasing the sensitivity of those tumors to the cytotoxic effects of canfosfamide. Following activation, the apoptotic activity of canfosfamide is mediated through the stress response pathway, resulting in the induction of cellular apoptosis. Human cancer cells exposed to canfosfamide demonstrate activation of mitogen- activated protein (MAP) kinase MKK4, p38 kinase, jun-N-terminal kinase (JNK) and caspase 3. The cytotoxic activity of canfosfamide has been demonstrated in vitro and in vivo against a variety of human cancer cell lines, including ovarian cancer cells (OVCAR3).

A phase II trial involving 34 patients with platinum-refractory or platinum-resistant ovarian cancer reported that $15 \%$ of patients had an objective response and $50 \%$ of patients had disease stabilization [40]. Three phase III trials in platinum-resistant ovarian cancer were undertaken in an attempt to define the potential role of canfosfamide in ovarian cancer therapeutics: TLK286 versus liposomal doxorubicin or topotecan (ASSIST-1,41); TLK286 plus carboplatin versus liposomal doxorubicin (ASSIST-3,42) and TLK286 plus liposomal doxorubicin versus liposomal doxorubicin alone (ASSIST-5,43). Unfortunately, none of these studies showed superior efficacy of canfosfamide compared to standard treatment.

\subsection{Increased DNA repair}

The cytotoxicity of cisplatin is attributed to the formation of cisplatin-DNA adducts, and to the induction of DNA damage. The balance between DNA damage to DNA repair dictates tumor cell death or survival after cisplatin therapy. Depending on the type of damage inflicted on the DNA structure, different DNA repair mechanisms have the ability to restore these lesions and remove the platinum-DNA adducts from the tumor DNA [44]. The major pathway in the repair of DNA damage is the nucleotide excision repair (NER) system. NER is one of 
five separate DNA repair mechanisms that also include mismatch repair (MMR), homologous recombination repair (HR), base excision repair (BER) and translesion synthesis. The preponderance of one repair mechanism over another may also change in different tumor types.

\subsubsection{Nucleotide Excision Repair (NER)}

The nucleotide excision repair (NER) pathway is predominantly responsible for repairing platinum-DNA adducts in cellular DNA. Several proteins interact in a coordinated fashion to recognize damage and further repair of the DNA (Figure 2). One of these proteins is excision repair cross-complementation group 1 (ERCC1). This 33-kD protein, mainly coupled with XPF (Xeroderma Pigmentosum-F protein) acts in the rate-limiting incision step that cleaves the DNA strand before DNA polymerases and ligases act to reconstitute double-strand integrity. Different studies with ovarian cancer cell lines have demonstrated that high ERCC1 mRNA expression is correlated with increased capacity of cells to repair cisplatin-induced DNA damage, thus conferring resistance to the drug. Further, transfection experiments using ERCC1 antisense vectors in both cell lines and mice have shown increased sensitivity to platinum $[45,46,47]$.

There is growing interest in evaluating the potential role of ERCC1 as a biomarker of platinum resistance in ovarian cancer. However, despite multiple studies evaluating the association between ERCC1 protein expression or even single nucleotide polymorphisms and clinical outcome, no definitive conclusion has yet been reached regarding the predictive and/or prognostic role of ERRCC1 in the management of EOC $[48,49]$.

\subsubsection{DNA mismatch repair}

The mismatch repair (MMR) system is a strand-specific DNA repair mechanism involved in the post-replicative repair of the errors made by DNA polymerases and in charge of eliminating single-base mismatches and insertion-deletion loops that have escaped the proofreading back-up mechanisms.

Loss of function of the cellular mismatch repair system (MMR) can partially contribute to develop DNA damage tolerance. Unaltered, MMR scans newly synthesized DNA and removes mismatches that result from nucleotide incorporation errors made by the DNA polymerases. The repair process consists of 3 steps - initiation, excision, and re-synthesisthat involve several proteins: MLH1, MSH2, MSH3, MSH6, and PMS2. Inactivation of MMR leads to the occurrence of unrepaired deletions in mononucleotide and dinucleotide repeats, resulting in variable length repeats. This phenomenon is called microsatellite instability (MSI), which can be caused by genetic or epigenetic inactivation and has been postulated as a potential marker for MMR deficiency. DNA methylation changes in plasma have been suggested as another rationale of chemotherapy resistance in OEC after treatment (acquired MLH1 methylation) [50].

MMR deficient human cancer cell lines tolerate cytotoxic drugs, suggesting that loss of MMR could cause platinum resistance [51]. Most MMR-deficient cancers have mutations in MLH1 or MSH2. Samimi et al [52] investigated MLH1 and MSH2 expression in paired ovarian tumor 


\section{A. Recognition of the DNA damage}
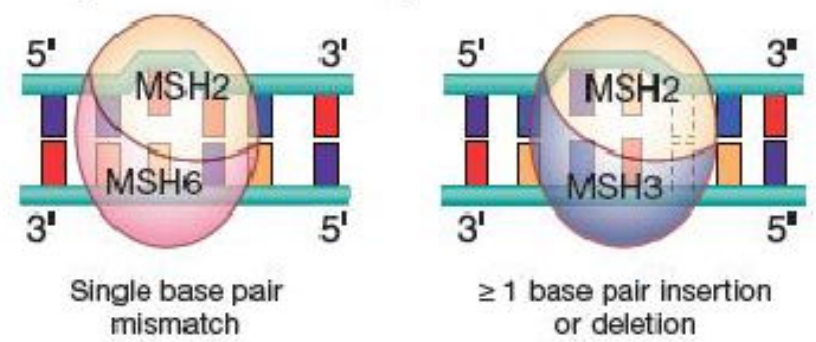

\section{B. Excision and resynthesis}

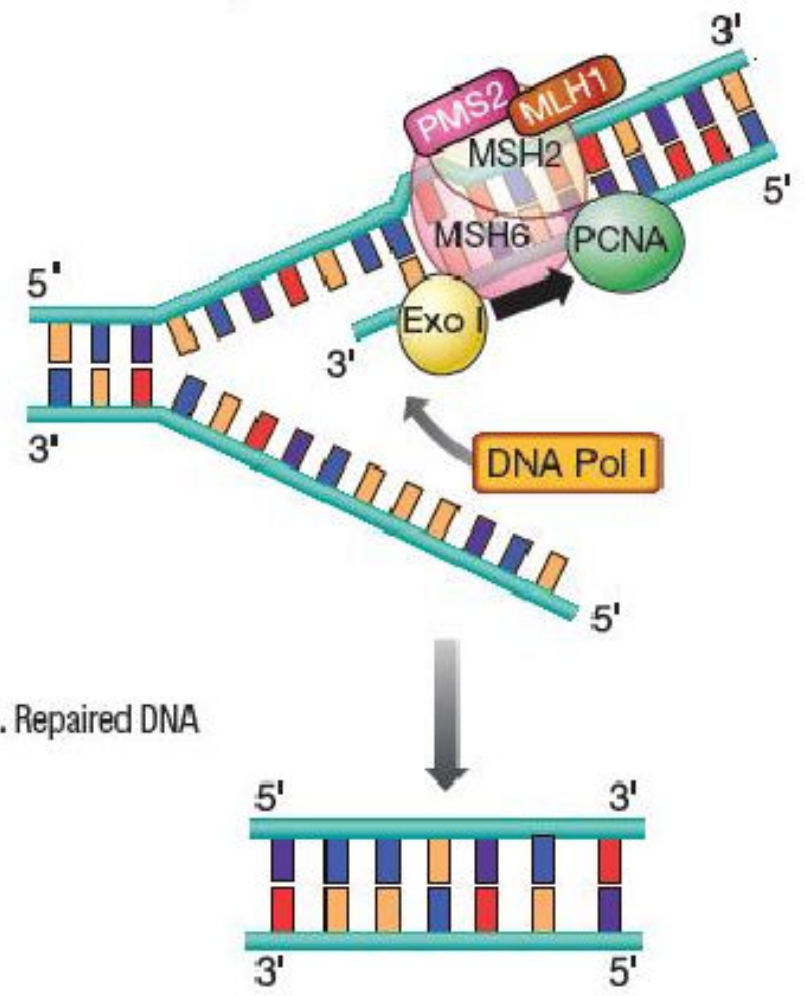

Figure 2. Schematic Representation of the Mismatch Repair Pathway (Adapted with permission from Diaz-Padilla I, Poveda A. Clin Ovarian Cancer Other Gynecol Malig 2010, 3(1):29-35.) Base-base mismatches are the most frequent errors associated with microsatellites (repetitive sequences of mononucleotide, dinucleotide, or higher-order nucleotide repeats distributed throughout the human genome). The mismatch repair system is responsible for the surveillance and correction of errors introduced in microsatellites. Mismatch repair proteins: MLH1, MSH2, MSH3, MSH6, PMS2. Exo 1, exonuclease; DNA Pol, DNA polymerase $\delta$; PCNA, proliferating cell nuclear antigen. 
sections from 54 ovarian cancer patients before and after platinum-based therapy by using immunohistochemical staining techniques. These authors demonstrated associations between MLH1 and MSH2 protein expression and clinical parameters known to be of prognostic significance as well as response to treatment and overall survival. MLH1 and MSH2 staining decreased significantly after platinum-based therapy. Hypermethylation of the MLH1 promoter has also been identified as a casual event in sporadic MMR-deficient malignant tumors. In ovarian cancer, it is estimated that about $10 \%$ of cases are related to this molecular pathway [53], although the methodology and definitions when assessing MSI in ovarian cancer are heterogeneous and not prospectively validated. The frequency of MMR dysfunction seems to vary depending on the histological subtype, being higher in endometrioid (19\%) and mucinous (17\%) subtypes. It is an assumption that MMR deficiency might be a tumor-initiating phenomenon in ovarian cancer, similar to colorectal and endometrial tumors. However, MMR deficient ovarian cancers have been only poorly characterized to date with respect to their epidemiological, molecular and clinical features.

Only a few studies have found a consistent relationship between MMR inactivation and platinum-based chemotherapy resistance (primarily down-regulation or mutations in MMR genes MLH1, MSH2 or MSH1) [50, 54,55,56].

This resistance to cisplatin can be circumvented using a DNA demethylating agent such as $2^{\prime}$ deoxy-5-azacytidine (decitabine; Dacoge, MGI Pharma) in combination with cisplatin or carboplatin to reverse this resistance mechanism [57]. Two phase II clinical trials have tested the combination of carboplatin and decitabine in recurrent Platinum-resistant OC patients with different conclusions [58,59].

\subsubsection{Homologous recombination repair pathway}

Platinum-based chemotherapy causes inter-strand DNA cross-linking which cause DNA double-strand breaks (DSBs) during DNA replication. DSBs are one of the most toxic lesions to DNA. This is because it affects both strands of the duplex, thus no intact complimentary strand is available as a template for repair. When such lesions are not repaired the cell undergoes apoptosis. If the reparation is not done appropriately, secondary lesions can occur, such as mutations and/or deletions. Cells have evolved two major pathways for the repair of DSBs: non-homologous end-joining (NHEJ) and homologous recombination (HR). The HR system is the preferred system by cells when it comes to repair DSBs. It is a highly conserved system, generally regarded as error-free, that requires an intact sister chromatid to act as template for correct repair of the break without loss of sequence information. As such, HR takes place in G2 and S phases of the cell cycle.

The BRCA1 gene is located on chromosome $17 \mathrm{q} 21$. The BRCA1 protein is a component of a number of supercomplexes, each of which plays a role in DNA damage response activation, cell cycle checkpoint activation and/or DSB repair. Some of the key components of this repair process are proteins such as BRCA2, RAD51 and PALB2. Actually, the interaction between specific domains of BRCA1 and PALB2 is key in the reparation of DBSs. Thus, mutations in domains of BRCA1 can potentially abolish its PALB2-binding activity, resulting in compromised HR function. These mutations have been found in BRCA1-mutated tumors, implying 
that loss of this specific BRCA1 function in DSB repair is source of the genomic instability and tumorigenesis observed in this subset of BRCA1 mutation carriers.

The BRCA2 gene is located on chromosome 13q. The BRCA2 protein has its primary function in HR and its based upon its ability to bind to the strand invasion recombinase, RAD51. In fact, recruitment of RAD51 to sites of DNA damage requires BRCA2, and BRCA2-deficient cells exhibit genomic instability.

Despite only $5-10 \%$ of epithelial ovarian cancer has an inherited background, more than $90 \%$ of hereditary ovarian tumors bear BRCA1/2 mutations. It has been described that these tumors are generally of serous histology, and high-grade. They usually present at younger ages, and more recently, it has been described that BRCA-mutated tumors have better prognosis. $[60,61,62]$. It is relevant to note that up to $55 \%$ of sporadic epithelial ovarian tumors have some sort of BRCA dysfunction. This has been named as BRCAness, and it may have important clinical consequences. One of the reasons behind this better outcome relies on a higher sensitivity to platinum compounds $[63,64]$. However, BRCA1/2-mutated also develop platinum resistance. One possible explanation is in relation with the production of secondary intragenic mutations in BRCA1/2 that restore these genetic expressions and HR function correcting the open reading frames of mutated BRCA1/2 [65,66,67]. However BRCA1/2 restoration does not explain all cases of cisplatin resistance so investigations in other mechanisms of chemo-resistance in BRCA-deficient ovarian cancer cells are needed.

Recently, PARP inhibitors have been developed as an important novel strategy for the treatment of BRCA mutation-associated ovarian and breast cancer. The rationale for this approach is that by inhibiting BER, these agents can prevent repair that occurs after cytotoxic chemotherapy that causes single-strand DNA breaks, and also they can work by creating "synthetic lethality" in cells which have lost one mechanism of DNA repair. In the absence of HR, inhibition of PARP results in poor repair of these lesions and apoptosis, increasing around 1000 -fold the sensitivity in cells that are BRCA1 or BRCA2 deficient $[68,69,70]$. Although olaparib and veliparib are the most widely studied in ovarian cancer $[71,72,73,74,75]$, other PARP inhibitors are in development such as BSI-201, AG014699, CEP9722, MK4827, E7016, LT673, to name just a few.

\section{Conclusion and future directions}

Chemotherapy resistance is the ultimate reason for tumor recurrence. Relapsed ovarian cancer is an incurable disease where chemotherapy plays a major therapeutic role. Platinum agents, likely in conjunction with taxanes, are the most active cytotoxic drugs in ovarian cancer. Traditionally, ovarian cancer recurrence has been classified according to the time elapsed from the last dose of platinum. Thus, relapses occurring more than six months from the last dose of platinum are generally re-treated with a platinum combination. Responses to a platinum rechallenge tend to be similar to the initial response, and the longer the platinum-free interval is the better the responses are. The so-called "platinum-sensitive" patients have better 
prognosis than women whose relapse is shorter than six months. For this group of patients therapeutic options are limited and usually consist in non-platinum agents.

The development of platinum resistance is a multifactorial and complex molecular process. Understanding the molecular basis of this mechanism would help potentially in selecting patients who are likely to have platinum-resistance tumors for alternate non-platinum containing regimens. This would spare women from unnecessary toxic effects and ineffective treatments. One potential scenario where the application of a molecular selection of patients by platinum sensitivity would be at initial presentation. A substantial number of advanced ovarian cancer patients undergo neoadjuvant chemotherapy prior to debulking surgery. Such chemotherapy consists of platinum and a taxane doublet. Despite most patients do have a major response to primary chemotherapy, about $20-30 \%$ fail to respond or progress.

The development of platinum resistance seems a dynamic process. Patients who initially respond to platinum-based chemotherapy end up becoming resistant. This suggests that we may need to investigate the mechanisms at several time points of the disease course. It is likely that primary platinum resistance is a molecular phenomenon different from secondary (and subsequent) platinum resistance. At this point, it is key that reliable biomarkers can be identified to better define platinum resistance. The quest for a bonafide biomarker of platinum resistance in ovarian cancer has been so far disappointing. It may well be the case that several markers need to be jointly studied, since platinum resistance is not a one-step molecular event. Further validation in large (ideally prospective) cohorts and in randomized phase III trials will be still needed. It will be difficult though to extrapolate results of platinum sensitivity when other agents are given concomitantly. It is not possible to rule out the potential influence of cytotoxics with similar mechanisms of action or biologics with the potential of modifying the tumor microenvironment. Unraveling the mechanisms of resistance to platinum (and other chemotherapy agents) in ovarian cancer is a very difficult task. However, its potential clinical benefits are worth such tremendous joint basic and clinical research effort.

\section{Author details}

\section{Gonzalo Tapia ${ }^{1}$ and Ivan Diaz-Padilla ${ }^{2 *}$}

*Address all correspondence to: ivandpadilla@hospitaldemadrid.com

1 Division of Medical Oncology, Gregorio Marañón University Hospital, Madrid, Spain

2 Division of Medical Oncology, Centro Integral Oncológico Clara Campal, Madrid, Spain

Disclosures: The authors have no conflict of interest 


\section{References}

[1] Siegel R, Naishadham D, Jemal A. Cancer Statistics , 2012. Cancer Journal The (Internet). Wiley Online Library; 2012;62(1):10-29. Available from: http:// www.ncbi.nlm.nih.gov/pubmed/22237781

[2] McGuire WP, Hoskins WJ, Brady MF, Kucera PR, Partridge EE, Look KY, et al. Cyclophosphamide and cisplatin compared with paclitaxel and cisplatin in patients with stage III and stage IV ovarian cancer. (Internet). The New England Journal of Medicine. 1996 p. 1-6. Available from: http://www.ncbi.nlm.nih.gov/pubmed/ 7494563

[3] Bristow RE, Tomacruz RS, Armstrong DK, Trimble EL, Montz FJ. Survival effect of maximal cytoreductive surgery for advanced ovarian carcinoma during the platinum era: a meta-analysis. Journal of Clinical Oncology (Internet). 2002;20(5):1248-59. Available from: http://www.ncbi.nlm.nih.gov/pubmed/11870167

[4] Muggia FM, Braly PS, Brady MF, Sutton G, Niemann TH, Lentz SL, et al. Phase III randomized study of cisplatin versus paclitaxel versus cisplatin and paclitaxel in patients with suboptimal stage III or IV ovarian cancer: a gynecologic oncology group study. (Internet). Journal of Clinical Oncology. 2000 p. 106-15. Available from: http:// www.ncbi.nlm.nih.gov/pubmed/10623700

[5] Ozols RF, Bundy BN, Greer BE, Fowler JM, Clarke-Pearson D, Burger RA, et al. Phase III trial of carboplatin and paclitaxel compared with cisplatin and paclitaxel in patients with optimally resected stage III ovarian cancer: a Gynecologic Oncology Group study. (Internet). Journal of Clinical Oncology. Nature Publishing Group; 2003 p. 3194-200. Available from: http://www.ncbi.nlm.nih.gov/pubmed/12860964

[6] Thigpen JT, Vance RB, Khansur T. Second-line chemotherapy for recurrent carcinoma of the ovary. Cancer. 1993;71(4 Suppl):1559-64.

[7] Du Bois A, Quinn M, Thigpen T, Vermorken J, Avall-Lundqvist E, Bookman M, et al. 2004 consensus statements on the management of ovarian cancer: final document of the 3rd International Gynecologic Cancer Intergroup Ovarian Cancer Consensus Conference (GCIG OCCC 2004). Annals of oncology official journal of the European Society for Medical Oncology ESMO (Internet). 2005. p. viii7-viii12. Available from: http://www.ncbi.nlm.nih.gov/pubmed/16239238

[8] Ledermann JA, Kristeleit RS. Optimal treatment for relapsing ovarian cancer. Annals of oncology official journal of the European Society for Medical Oncology ESMO (Internet). OXFORD UNIV PRESS; 2010;21 Suppl 7(Supplement 7):vii218-i222. Available from: http://discovery.ucl.ac.uk/539589/

[9] Harter P, Du Bois A, Hahmann M, Hasenburg A, Burges A, Loibl S, et al. Surgery in recurrent ovarian cancer: the Arbeitsgemeinschaft Gynaekologische Onkologie 
(AGO) DESKTOP OVAR trial. (Internet). Annals of Surgical Oncology. 2006 p. 1702 10. Available from: http://www.ncbi.nlm.nih.gov/pubmed/17009163

[10] Jamieson ER, Lippard SJ. Structure, Recognition, and Processing of Cisplatin-DNA Adducts. Chemical Reviews (Internet). 1999;99(9):2467-98. Available from: http:// pubs.acs.org/doi/abs/10.1021/cr980421n

[11] Siddik ZH. Cisplatin: mode of cytotoxic action and molecular basis of resistance. Oncogene (Internet). Nature Publishing Group; 2003;22(47):7265-79. Available from: http://www.ncbi.nlm.nih.gov/pubmed/14576837

[12] Jordan P, Carmo-Fonseca M. Molecular mechanisms involved in cisplatin cytotoxicity. Cellular and Molecular Life Sciences (Internet). 2000;57(8):1229-35. Available from: http://dx.doi.org/10.1007/PL00000762

[13] Mitochondria F, Biochem EJ. The mitochondrion in apoptosis: how Pandora ' s box opens. Cell (Internet). 2001;2(January):67-71. Available from: http:// www.ncbi.nlm.nih.gov/pubmed/11413468

[14] Olivero OA, Chang PK, Lopez-Larraza DM, Semino-Mora MC, Poirier MC. Preferential formation and decreased removal of cisplatin-DNA adducts in Chinese hamster ovary cell mitochondrial DNA as compared to nuclear DNA. Mutation Research. 1997;391(1-2):79-86.

[15] Murata T, Hibasami H, Maekawa S, Tagawa T, Nakashima K. Preferential binding of cisplatin to mitochondrial DNA and suppression of ATP generation in human malignant melanoma cells. Biochemistry International. 1990;20(5):949-55.

[16] Ishida S, Lee J, Thiele DJ, Herskowitz I. Uptake of the anticancer drug cisplatin mediated by the copper transporter Ctr1 in yeast and mammals. Proceedings of the National Academy of Sciences of the United States of America (Internet). National Academy of Sciences; 2002;99(22):14298-302. Available from: http://www.pubmedcentral.nih.gov/articlerender.fcgi?artid=137878\&tool=pmcentrez\&rendertype=abstract

[17] Safaei R, Otani S, Larson BJ, Rasmussen ML, Howell SB. Transport of cisplatin by the copper efflux transporter ATP7B. Molecular Pharmacology (Internet). 2008;73(2):4618. Available from: http://www.ncbi.nlm.nih.gov/entrez/query.fcgi?cmd=Retrieve\&db=PubMed\&dopt=Citation\&list_uids $=17978167$

[18] Tsang RY, Al-Fayea T, Au H-J. Cisplatin overdose: toxicities and management. Drug safety an international journal of medical toxicology and drug experience (Internet). Adis International Ltd (41 Centorian Drive, Private Bag 65901, Mairangi Bay, Auckland 10 1311, New Zealand); 2009;32(12):1109-22. Available from: http:// www.ncbi.nlm.nih.gov/pubmed/19916578

[19] Stewart L, Advanced Ovarian Cancer Trialists Group. Chemotherapy for advanced ovarian cancer. Advanced Ovarian Cancer Trialists Group. Cochrane database of sys- 
tematic reviews Online (Internet). 2000;(2):CD001418. Available from: http:// www.ncbi.nlm.nih.gov/pubmed/10796788

[20] Neijt JP, Engelholm SA, Tuxen MK, Sorensen PG, Hansen M, Sessa C, et al. Exploratory phase III study of paclitaxel and cisplatin versus paclitaxel and carboplatin in advanced ovarian cancer. (Internet). Journal of Clinical Oncology. Nature Publishing Group; 2000 p. 3084-92. Available from: http://www.ncbi.nlm.nih.gov/pubmed/ 10963636

[21] Du Bois A, Lück H-J, Meier W, Adams H-P, Möbus V, Costa S, et al. A randomized clinical trial of cisplatin/paclitaxel versus carboplatin/paclitaxel as first-line treatment of ovarian cancer. (Internet). Journal Of The National Cancer Institute. 2003 p. 13209. Available from: http://www.ncbi.nlm.nih.gov/pubmed/20937992

[22] Aaronson NK, Ahmedzai S, Bergman B, Bullinger M, Cull A, Duez NJ, et al. The European Organization for Research and Treatment of Cancer QLQ-C30: a quality-oflife instrument for use in international clinical trials in oncology. Journal Of The National Cancer Institute (Internet). Oxford University Press; 1993;85(5):365-76. Available from: http://jnci.oxfordjournals.org/content/85/5/365.short

[23] Rabik CA, Dolan ME. Molecular mechanisms of resistance and toxicity associated with platinating agents. Cancer Treatment Reviews (Internet). 2007;33(1):9-23. Available from: http://www.pubmedcentral.nih.gov/articlerender.fcgi?artid $=1855222 \&$ tool=pmcentrez\&rendertype $=$ abstract

[24] Holzer AK, Manorek GH, Howell SB. Contribution of the major copper influx transporter CTR1 to the cellular accumulation of cisplatin, carboplatin, and oxaliplatin. Molecular Pharmacology (Internet). ASPET; 2006;70(4):1390-4. Available from: http://molpharm.aspetjournals.org/cgi/content/abstract/70/4/1390

[25] Song I-S, Savaraj N, Siddik ZH, Liu P, Wei Y, Wu CJ, et al. Role of human copper transporter Ctr1 in the transport of platinum-based antitumor agents in cisplatin-sensitive and cisplatin-resistant cells. Molecular Cancer Therapeutics (Internet). AACR; 2004;3(12):1543-9. Available from: http://www.ncbi.nlm.nih.gov/entrez/query.fcgi? cmd=Retrieve\&db=PubMed\&dopt=Citation\&list_uids=15634647

[26] Holzer AK, Katano K, Klomp LWJ, Howell SB. Cisplatin rapidly down-regulates its own influx transporter hCTR1 in cultured human ovarian carcinoma cells. Clinical Cancer Research (Internet). 2004;10(19):6744-9. Available from: http:// www.ncbi.nlm.nih.gov/pubmed/15475465

[27] Samimi G, Katano K, Holzer AK, Safaei R, Howell SB. Modulation of the cellular pharmacology of cisplatin and its analogs by the copper exporters ATP7A and ATP7B. Molecular Pharmacology (Internet). 2004;66(1):25-32. Available from: http:// molpharm.aspetjournals.org/cgi/content/abstract/66/1/25

[28] Samimi G, Varki NM, Wilczynski S, Safaei R, Alberts DS, Howell SB. Increase in expression of the copper transporter ATP7A during platinum drug-based treatment is 
associated with poor survival in ovarian cancer patients. Clinical Cancer Research. 2003;9(16 Pt 1):5853-9.

[29] Nakayama K, Kanzaki A, Ogawa K, Miyazaki K, Neamati N, Takebayashi Y. Copper-transporting P-type adenosine triphosphatase (ATP7B) as a cisplatin based chemoresistance marker in ovarian carcinoma: comparative analysis with expression of MDR1, MRP1, MRP2, LRP and BCRP. International journal of cancer Journal international du cancer (Internet). 2002;101(5):488-95. Available from: http:// www.ncbi.nlm.nih.gov/pubmed/12216079

[30] Borst P, Rottenberg S, Jonkers J. How do real tumors become resistant to cisplatin? Cell cycle Georgetown Tex (Internet). Landes Bioscience; 2008;7(10):1353-9. Available from: http://www.ncbi.nlm.nih.gov/pubmed/18418074

[31] Korita P V, Wakai T, Shirai Y, Matsuda Y, Sakata J, Takamura M, et al. Multidrug resistance-associated protein 2 determines the efficacy of cisplatin in patients with hepatocellular carcinoma. Oncology Reports. 2010 p. 965-72.

[32] Kool M, De Haas M, Scheffer GL, Scheper RJ, Van Eijk MJ, Juijn JA, et al. Analysis of expression of cMOAT (MRP2), MRP3, MRP4, and MRP5, homologues of the multidrug resistance-associated protein gene (MRP1), in human cancer cell lines. Cancer Research (Internet). 1997;57(16):3537-47. Available from: http:// www.ncbi.nlm.nih.gov/pubmed/9270026

[33] Gottesman MM, Ling V. The molecular basis of multidrug resistance in cancer: the early years of P-glycoprotein research. FEBS Letters (Internet). 2006;580(4):998-1009. Available from: http://www.ncbi.nlm.nih.gov/pubmed/16405967

[34] Fracasso PM, Brady MF, Moore DH, Walker JL, Rose PG, Letvak L, et al. Phase II study of paclitaxel and valspodar (PSC 833) in refractory ovarian carcinoma: a gynecologic oncology group study. Journal of Clinical Oncology (Internet). 2001;19(12): 2975-82. Available from: www.ncbi.nlm.nih.gov/pubmed/11408492

[35] Hoffmann A-C, Wild P, Leicht C, Bertz S, Danenberg KD, Danenberg P V, et al. MDR1 and ERCC1 Expression Predict Outcome of Patients with Locally Advanced Bladder Cancer Receiving. Trial (Internet). 2010;12(8):628-36. Available from: http:// www.pubmedcentral.nih.gov/articlerender.fcgi?artid=2915407\&tool=pmcentrez\&rendertype $=$ abstract

[36] Rodrigues FFO, Santos RE, Melo MB, Silva MALG, Oliveira AL, Rozenowicz RL, et al. Correlation of polymorphism C3435T of the MDR-1 gene and the response of primary chemotherapy in women with locally advanced breast cancer. Genetics and molecular research GMR (Internet). 2008;7(1):1117-21. Available from: http:// www.ncbi.nlm.nih.gov/entrez/query.fcgi?cmd=Retrieve\&db=PubMed\&dopt=Citation\&list_uids=12684679 
[37] Kelland L. The resurgence of platinum-based cancer chemotherapy. Nature Reviews Cancer (Internet). Nature Publishing Group; 2007;7(8):573-84. Available from: http:// www.ncbi.nlm.nih.gov/pubmed/17625587

[38] Sakamoto M, Kondo A, Kawasaki K, Goto T, Sakamoto H, Miyake K, et al. Analysis of gene expression profiles associated with cisplatin resistance in human ovarian cancer cell lines and tissues using cDNA microarray. Human cell official journal of Human Cell Research Society (Internet). 2001;14(4):305-15. Available from: http:// www.ncbi.nlm.nih.gov/entrez/query.fcgi?cmd=Retrieve\&db=PubMed\&dopt=Citation\&list_uids=11925933

[39] Li M, Balch C, Montgomery JS, Jeong M, Chung JH, Yan P, et al. Integrated analysis of DNA methylation and gene expression reveals specific signaling pathways associated with platinum resistance in ovarian cancer. BMC medical genomics (Internet). BioMed Central; 2009;2(1):34. Available from: http://www.pubmedcentral.nih.gov/ articlerender.fcgi?artid=2712480\&tool=pmcentrez\&rendertype=abstract

[40] Kavanagh JJ, Gershenson DM, Choi H, Lewis L, Patel K, Brown GL, et al. Multi-institutional phase 2 study of TLK286 (TELCYTA, a glutathione S-transferase P1-1 activated glutathione analog prodrug) in patients with platinum and paclitaxel refractory or resistant ovarian cancer. (Internet). International journal of gynecological cancer official journal of the International Gynecological Cancer Society. Nature Publishing Group; 2005 p. 593-600. Available from: http://dx.doi.org/10.1111/j. 1525-1438.2005.00114.x

[41] Vergote I, Finkler N, Del Campo J, Lohr A, Hunter J, Matei D, et al. Phase 3 randomised study of canfosfamide (Telcyta, TLK286) versus pegylated liposomal doxorubicin or topotecan as third-line therapy in patients with platinum-refractory or resistant ovarian cancer. (Internet). European Journal of Cancer. Elsevier Ltd; 2009 p. 2324-32. Available from: http://www.ncbi.nlm.nih.gov/pubmed/19515553

[42] Rose P. Canfosfamide (C, TLK286) plus carboplatin (P) vs. liposomal doxorubicin (D) as 2nd line therapy of platinum (P) resistant ovarian cancer (OC): phase 3 study results. Journal of Clinical Oncology. Nature Publishing Group; 2007;25(Suppl.):5529.

[43] Vergote I, Finkler NJ, Hall JB, Melnyk O, Edwards RP, Jones M, et al. Randomized phase III study of canfosfamide in combination with pegylated liposomal doxorubicin compared with pegylated liposomal doxorubicin alone in platinum-resistant ovarian cancer. (Internet). International journal of gynecological cancer official journal of the International Gynecological Cancer Society. 2010 p. 772-80. Available from: http://content.wkhealth.com/linkback/openurl?sid=WKPTLP:landingpage\&an=00009577-201007000-00013

[44] Reed E. Platinum-DNA adduct, nucleotide excision repair and platinum based anticancer chemotherapy. Cancer Treatment Reviews (Internet). 1998;24(5):331-44. Available from: http://www.ncbi.nlm.nih.gov/pubmed/9861196 
[45] Selvakumaran M, Pisarcik DA, Bao R, Yeung AT, Hamilton TC. Enhanced Cisplatin Cytotoxicity by Disturbing the Nucleotide Excision Repair Pathway in Ovarian Cancer Cell Lines. Cancer Research (Internet). 2003;63(6):1311-6. Available from: www.ncbi.nlm.nih.gov/pubmed/12649192

[46] Dabholkar M, Vionnet J, Bostick-Bruton F, Yu JJ, Reed E. Messenger RNA levels of $\mathrm{XPAC}$ and ERCC1 in ovarian cancer tissue correlate with response to platinum-based chemotherapy. Journal of Clinical Investigation (Internet). 1994;94(2):703-8. Available from: http://www.pubmedcentral.nih.gov/articlerender.fcgi?artid=296149\&tool=pmcentrez\&rendertype=abstract

[47] Kohn EC, Sarosy G, Bicher A, Link C, Christian M, Steinberg SM, et al. Dose-intense taxol: high response rate in patients with platinum-resistant recurrent ovarian cancer. (Internet). Journal Of The National Cancer Institute. 1994 p. 18-24. Available from: http://www.ncbi.nlm.nih.gov/pubmed/7505830

[48] Smith S, Su D, Rigault De La Longrais IA, Schwartz P, Puopolo M, Rutherford TJ, et al. ERCC1 genotype and phenotype in epithelial ovarian cancer identify patients likely to benefit from paclitaxel treatment in addition to platinum-based therapy. Journal of Clinical Oncology (Internet). 2007;25(33):5172-9. Available from: http:// www.ncbi.nlm.nih.gov/pubmed/18024864

[49] Krivak TC, Tian C, Rose GS, Armstrong DK, Maxwell GL. A Gynecologic Oncology Group Study of serum CA-125 levels in patients with stage III optimally debulked ovarian cancer treated with intraperitoneal compared to intravenous chemotherapy: an analysis of patients enrolled in GOG 172. (Internet). Gynecologic Oncology. Elsevier Inc.; 2009 p. 81-5. Available from: http://www.ncbi.nlm.nih.gov/pubmed/ 19945740

[50] Gifford G, Paul J, Vasey PA, Kaye SB, Brown R. The acquisition of hMLH1 methylation in plasma DNA after chemotherapy predicts poor survival for ovarian cancer patients. Clinical Cancer Research (Internet). American Association for Cancer Research; 2004;10(13):4420-6. Available from: http://eprints.gla.ac.uk/18729/

[51] Anthoney DA, Kaye SB. Drug resistance: the clinical perspective. Methods in Molecular Medicine (Internet). 1999;28:1-15. Available from: http://www.ncbi.nlm.nih.gov/ pubmed/21374022

[52] Samimi G, Fink D, Varki NM, Husain A, Hoskins WJ, Alberts DS, et al. Analysis of MLH1 and MSH2 expression in ovarian cancer before and after platinum drug-based chemotherapy. Clinical Cancer Research (Internet). 2000;6(4):1415-21. Available from: http://clincancerres.aacrjournals.org/cgi/content/full/6/4/1415

[53] Murphy MA, Wentzensen N. Frequency of mismatch repair deficiency in ovarian cancer: A systematic review. International journal of cancer Journal international du cancer (Internet). 2010;1-25. Available from: http://www.ncbi.nlm.nih.gov/entrez/ query.fcgi?db=pubmed\&cmd=Retrieve\&dopt=AbstractPlus\&list_uids=21140452 
[54] Helleman J, Van Staveren IL, Dinjens WN, Van Kuijk PF, Ritstier K, Ewing PC, et al. Mismatch repair and treatment resistance in ovarian cancer. BMC Cancer (Internet). BioMed Central; 2006;6(1):201. Available from: http://www.pubmedcentral.nih.gov/ articlerender.fcgi?artid=1557864\&tool=pmcentrez\&rendertype=abstract

[55] Watanabe Y, Koi M, Hemmi H, Hoshai H, Noda K. A change in microsatellite instability caused by cisplatin-based chemotherapy of ovarian cancer. British Journal of Cancer (Internet). Nature Publishing Group; 2001;85(7):1064-9. Available from: http://eutils.ncbi.nlm.nih.gov/entrez/eutils/elink.fcgi?

dbfrom=pubmed\&id=11592780\&retmode $=$ ref\&cmd=prlinks

[56] Fink D, Nebel S, Norris PS, Baergen RN, Wilczynski SP, Costa MJ, et al. Enrichment for DNA mismatch repair-deficient cells during treatment with cisplatin. International journal of cancer Journal international du cancer. 1998;77(5):741-6.

[57] Brown R, Plumb JA. Demethylation of DNA by decitabine in cancer chemotherapy. Expert Review of Anticancer Therapy (Internet). 2010;4(4):501-10. Available from: http://eprints.gla.ac.uk/15879/

[58] Matei D, Fang F, Shen C, Schilder J, Arnold A, Zeng Y, et al. Epigenetic Resensitization to Platinum in Ovarian Cancer. Cancer Research (Internet). 2012;72(9):2197-205. Available from: http://cancerres.aacrjournals.org/cgi/doi/ 10.1158/0008-5472.CAN-11-3909

[59] Glasspool RM, Gore M, Rustin G, McNeish I, Wilson R, Pledge S, et al. Randomized phase II study of decitabine in combination with carboplatin compared with carboplatin alone in patients with recurrent advanced ovarian cancer. Journal of Clinical Oncology (Internet). 2009;27(15s):suppl; abstr 5562. Available from: http:// eprints.gla.ac.uk/42722/

[60] Ben David Y, Chetrit A, Hirsh-Yechezkel G, Friedman E, Beck BD, Beller U, et al. Effect of BRCA mutations on the length of survival in epithelial ovarian tumors. Journal of Clinical Oncology (Internet). 2002;20(2):463-6. Available from: http:// www.ncbi.nlm.nih.gov/pubmed/11786575

[61] Cass I, Baldwin RL, Varkey T, Moslehi R, Narod SA, Karlan BY. Improved survival in women with BRCA-associated ovarian carcinoma. Cancer (Internet). 2003;97(9): 2187-95. Available from: http://www.ncbi.nlm.nih.gov/pubmed/12712470

[62] Tan DSP, Rothermundt C, Thomas K, Bancroft E, Eeles R, Shanley S, et al. "BRCAness" syndrome in ovarian cancer: a case-control study describing the clinical features and outcome of patients with epithelial ovarian cancer associated with BRCA1 and BRCA2 mutations. Journal of Clinical Oncology (Internet). 2008;26(34):5530-6. Available from: http://www.ncbi.nlm.nih.gov/pubmed/18955455

[63] Yang D, Khan S, Sun Y, Hess K, Shmulevich I, Sood AK, et al. Association of BRCA1 and BRCA2 mutations with survival, chemotherapy sensitivity, and gene mutator phenotype in patients with ovarian cancer. Jama The Journal Of The American Medi- 
cal Association (Internet). 2011;306(14):1557-65. Available from: http:// www.ncbi.nlm.nih.gov/pubmed/21990299

[64] Weberpals J, Garbuio K, O’Brien A, Clark-Knowles K, Doucette S, Antoniouk O, et al. The DNA repair proteins BRCA1 and ERCC1 as predictive markers in sporadic ovarian cancer. International journal of cancer Journal international du cancer (Internet). Wiley Subscription Services, Inc., A Wiley Company; 2009;124(4):806-15. Available from: http://www.ncbi.nlm.nih.gov/pubmed/19035454

[65] Edwards SL, Brough R, Lord CJ, Natrajan R, Vatcheva R, Levine DA, et al. Resistance to therapy caused by intragenic deletion in BRCA2. Nature (Internet). Nature Publishing Group; 2008;451(7182):1111-5. Available from: http://www.ncbi.nlm.nih.gov/ pubmed/18264088

[66] Sakai W, Swisher EM, Karlan BY, Agarwal MK, Higgins J, Friedman C, et al. Secondary mutations as a mechanism of cisplatin resistance in BRCA2-mutated cancers. Nature (Internet). Nature Publishing Group; 2008;451(7182):1116-20. Available from: http://dx.doi.org/10.1038/nature06633

[67] Swisher EM, Sakai W, Karlan BY, Wurz K, Urban N, Taniguchi T. Secondary BRCA1 mutations in BRCA1-mutated ovarian carcinomas with platinum resistance. Cancer Research (Internet). 2008;68(8):2581-6. Available from: http://www.pubmedcentral.nih.gov/articlerender.fcgi?artid=2674369\&tool=pmcentrez\&rendertype=abstract

[68] Satoh MS, Poirier GG, Lindahl T. Dual function for poly(ADP-ribose) synthesis in response to DNA strand breakage. Biochemistry (Internet). 1994;33(23):7099-106. Available from: http://www.ncbi.nlm.nih.gov/pubmed/8003475

[69] Bryant HE, Schultz N, Thomas HD, Parker KM, Flower D, Lopez E, et al. Specific killing of BRCA2-deficient tumours with inhibitors of poly(ADP-ribose) polymerase. Nature (Internet). Nature Publishing Group; 2005;434(7035):913-7. Available from: http://www.ncbi.nlm.nih.gov/pubmed/15829966

[70] Farmer H, McCabe N, Lord CJ, Tutt ANJ, Johnson DA, Richardson TB, et al. Targeting the DNA repair defect in BRCA mutant cells as a therapeutic strategy. Nature (Internet). Nature Publishing Group; 2005;434(7035):917-21. Available from: http:// www.ncbi.nlm.nih.gov/pubmed/15829967

[71] Yap TA, Boss DS, Fong PC, Roelvink M, Tutt A, Carmichael J, et al. First in human phase I pharmacokinetic (PK) and pharmacodynamic (PD) study of KU-0059436 $(\mathrm{Ku})$, a small molecule inhibitor of poly ADP-ribose polymerase (PARP) in cancer patients (p), including BRCA1/2 mutation carriers. Journal of Clinical Oncology (Internet). Nature Publishing Group; 2007;25(Suppl.):3529. Available from: http:// meeting.ascopubs.org/cgi/content/abstract/25/18_suppl/3529

[72] Fong PC, Spicer J, Reade S, Reid A, Vidal L, Schellens JH, et al. Phase I pharmacokinetic (PK) and pharmacodynamic (PD) evaluation of a small molecule inhibitor of Poly ADP-Ribose Polymerase (PARP), KU-0059436 (Ku) in patients (p) with ad- 
vanced tumours. Journal of Clinical Oncology (Internet). Nature Publishing Group; 2006;24(Suppl.):3022. Available from: http://meeting.ascopubs.org/cgi/content/ abstract/24/18_suppl/3022

[73] Audeh MW, Penson RT, Friedlander M, Powell B, Bell-McGuinn KM, Scott C, et al. Phase II trial of the oral PARP inhibitor olaparib (AZD2281) in BRCA-deficient advanced ovarian cancer. J Clin Oncol Meeting Abstracts (Internet). 2009;27(15S):5500. Available from: http://meeting.ascopubs.org/cgi/content/abstract/27/15S/5500

[74] Kaye S, Kaufman B, Lubinski J, Matulonis U, Gourley C, Karlan B, et al. Phase II study of the oral parp inhibitor olaparib (AZD2281) versus liposomal doxorubicin in ovarian cancer patients with brca1 and/or BRCA2 mutations. Annals of Oncology (Internet). 2010;21:viii304. Available from: http://www.embase.com/search/results? subaction=viewrecord\&from=export\&id=L70303663

[75] Kummar S, Jiuping J, Morgan RJ, Lenz H-JD, Puhalla SL, Belani CP, et al. A Phase I Study of Veliparib in Combination with Metronomic Cyclophosphamide in Adults with Refractory Solid Tumors and Lymphomas. Clinical Cancer Research (Internet). 2012; Available from: http://www.ncbi.nlm.nih.gov/pubmed/22307137 
